\title{
Analysis of Tensile Strength, Hardness and Impact Energy of SAE1040 Steel Using Heat Treatment Processes
}

\author{
Qadir Bakhsh Jamali, ${ }^{1}$, Muswar Ali Farhad ${ }^{1}$, Abdul Sattar Jamali $^{1}$, Muhammad Sharif Jamali ${ }^{2}$, Arshad \\ Hussain $^{2}$, Fida Hussain ${ }^{2}$ \\ ${ }^{1}$ Department of Mechanical Engineering, QUEST, Nawabshah \\ ${ }^{2}$ Department of Mechanical Engineering, MUET, Jamshoro \\ ${ }^{*}$ Corresponding author: qjamali@quest.edu.pk
}

\begin{abstract}
A systematic study was carried out to improve the mechanical properties of medium carbon steel grade SAE 1040 by heat treatment processes. Test specimen were prepared according to ASTM standards. Test specimen were heat treated in Gas furnace at austenitization temperature of $700^{\circ} \mathrm{C}$ to obtain fully austenite structure, soaked for 90 minutes, cooled in air and furnace, and quenched in water separately. Mechanical properties such as hardness, tensile strength, yield strength, breaking strength, Young's Modulus, elongation and impact energy were investigated in this study. It was observed that water quenching enhances materials' hardness, tensile strength, yield strength, breaking strength and Young's Modulus while reducing the elongation and impact energy as compared with untreated specimen. Furnace cooling decreases materials' hardness, tensile strength, yield strength, breaking strength, Young's Modulus while increasing the elongation and impact energy as compared with untreated specimen. Air cooling improved the materials' mechanical properties such as hardness, tensile strength, yield strength, breaking strength, Young's Modulus, elongation and impact energy as compared with untreated specimen. The results of this study show that the heat treatment technique greatly influences the mechanical properties of medium carbon steel grade SAE 1040 .
\end{abstract}

Keywords-Heat treatment, mechanical properties, SAE 1040, air cooling, furnace cooling, water quenching.

\section{Introduction}

$\mathrm{T}$ HE initiation of industrial revolution implies that humanity has started to enter the steam era of metal machines. Throughout history, wealth, living standard and status of a nation within the international community have benefited directly from the manufacturing capability of the nation. Affordability and the quality of manufactured products enable transportation systems, health care, generation of energy and its distribution, construction, education, banking and almost every aspect of modern lifestyle [1]. Manufacturing encompasses the conversion of raw materials (which are commonly brought in plain or shapeless forms) into manufactured products. These products are manufactured with different shapes, structures and properties to meet various requirements

ISSN: 2523-0379 (Online), ISSN: 1605-8607 (Print)

DOI: 10.52584/QRJ.1802.05

This is an open access article published by Quaid-e-Awam University of Engineering Science \& Technology, Nawabshah, Pakistan under CC BY 4.0 International License.
[2].

Steel is the metal that is used the most on earth and the most recycled. Steel in its number of forms and alloys, from high temperature and stainless steel to flat carbon products to suit a wide range of applications, offers a wide range of properties. Steel is now being used in countless products because it has the combination of high strength from the metal and a comparatively lower cost of production. Transport, construction, packaging, appliances and industry sectors are the main division where steel is being widely used. Wide usage of steel is because of two main reasons: (1) it is rich in the earth's crust in the form of ferric oxide (Fe2O3) and little energy is needed to convert it to iron $(\mathrm{Fe})$, and (2) a wide range of micro-structures and other mechanical properties can be developed [3].

Heat treating involves manipulating solid metals or alloys by heating and cooling to acquire the necessary micro-structures by refining the size of grains 
and a combination of mechanical properties. Structural metal material's mechanical properties are the functions of its micro-structure with some chemical composition. The primary objective of heat treatment technique is to improve or control the mechanical properties by influencing the micro-structure to fulfill the requirements that are restricted to a specific object, either for use or to be subjected to a forming or machining technology [4]. Although, there are thousands of steel specifications, medium carbon steel contributes to more than three quarters of the overall steel output because it is a cheap, ductile and hard material with essential properties such as casting, working and machining which can also offer a wide range of properties through simple heat treatments. Medium carbon steel is a material of great versatility and utility. It can be machined and worked into complex shapes with minimal cost and good mechanical properties. In machining, various materials are accessible for manufacturing of machine parts in which medium carbon steel, because of its own mechanical properties (high strength and toughness etc.), plays a vital role in the manufacturing of crankshafts, couplings, gears, shafts, axles, bolts, studs, screwdrivers, pliers and many other engineering applications [3].

\section{Literature Review}

Specimen steel containing $0.2 \%, 0.4 \%$ and $0.6 \%$ carbon were heated at $977^{\circ} \mathrm{C}$ for 4 hour, specimen were then cooled in furnace and air and quenched in water separately. Cooling rate difference appears to have a dramatic effect on steel's micro-hardness depending on the carbon fraction in steels. By increasing the fraction of carbon in steel and cooling rate, the micro-hardness increases as a result of martensite phase formation and solid solution hardening. Therefore, heat treatment is being utilized to attain desired properties of steels, e.g., toughness, ductility or residual stress removal [3]. Specimen of steel grade AISI 1040 were heated at temperature of $723^{\circ} \mathrm{C}$ and $750^{\circ} \mathrm{C}$, and then cooled in still air and furnace and quenched in water. It was investigated whether hardness totally depends on temperature and method of cooling. The specimens quenched in water showed highest hardness value when compared with the air-and-furnace cooled specimens. Furnace cooling from austenitization temperature of $750^{\circ} \mathrm{C}$, indicated minimum hardness values [4]. Since steel contains $0.33 \%$ carbon, specimen were austenitized between $900^{\circ} \mathrm{C}-980^{\circ} \mathrm{C}$ and held for 45 minutes in a muffle oven, then immediately quenched in water and palm oil separately. Tensile strength and hardness was found to improve when compared with casted specimen. However, palm oil quenched specimens exhibited better mechanical properties combination compared other media-quenched specimen. This behavior is due to the fact that more undeviating and evenly distributed carbon particles in palm oil-quenched specimens result in the formation of an additional pearlite structure [5].

In this work, specimens from low, medium and high carbon steel grades were heated at $900^{\circ} \mathrm{C}$ for 20 minutes, then cooled in furnace and quenched in oil and water separately to improve the toughness of the material. Despite the heat treatment process, absorbed energy depends to some degree on the content of carbon in steel. Steel with a lower carbon content has the highest absorbed energy. The absorbed energy of low/medium carbon steel improves with the heat treatment process, but in case of high carbon steel, does not significantly improve the energy absorption with heat treatment. In fact, water-based caustic ants quench parts even faster than oil and water quenched, medium-carbon steel and low-carbon steel specimens show greater toughness than water quenching [10]. The study investigated the influence of tempering temperature on heat treated medium carbon steel (Grade C 35 Mn 75). Firstly, the specimen austenitized at a temperature of $900^{\circ} \mathrm{C}$ soaked for 1hour, then water quenched, and then followed by tempering at the temperature of $250^{\circ} \mathrm{C}, 350^{\circ} \mathrm{C}, 450^{\circ} \mathrm{C}, 550^{\circ} \mathrm{C}$ for each tempering time interval. The tempered specimen was found higher in tensile strength and hardness than the casted specimen. Tempered specimen gave an increase in the percentage of elongation and toughness, while decreasing the tensile strength and hardness as compared to the hardened specimen.

When tempering temperature increases, toughness or impact energy of the steel also gradually increases. The result shows a higher value of yield strength at a tempering temperature of $350^{\circ} \mathrm{C}$. The percentage of elongation has lower value at $450^{\circ} \mathrm{C}$ as compared to the other tempering temperature [6]. Researchers investigated the medium carbon steel, analyzed the specimen at temperature of $977^{\circ} \mathrm{C}$ for 4 hour, then cooled in furnace, air, water [3]. Specimen were heated at $723^{\circ} \mathrm{C}$ and $750^{\circ} \mathrm{C}$, and then cooled in still air, furnace, water [4]. Specimen were heated between $900^{\circ} \mathrm{C}-980^{\circ} \mathrm{C}$ held at for 45 minutes in a muffle oven then immediately quenched in water and palm oil separately [5]. In this study, specimen of medium carbon steel grade SAE 1040 were heated at the temperature of $700^{\circ} \mathrm{C}$, soaked for 90 minutes, cooled in furnace and air, and quenched in water. Improvement of the mechanical properties of steels by using heat treatment technique is used. In this technique, the heat treatment temperature and medium of cooling plays vital role in the improvement 


\begin{tabular}{|l|l|l|l|l|}
\hline $\mathbf{C}$ & Fe & Mn & P & S \\
\hline $0.37-0.44$ & $98.6-99$ & $0.60-0.90$ & 0.040 & 0.05 \\
\hline
\end{tabular}

TABLE 1: Chemical composition of SAE 1040 by wt. $\%$.

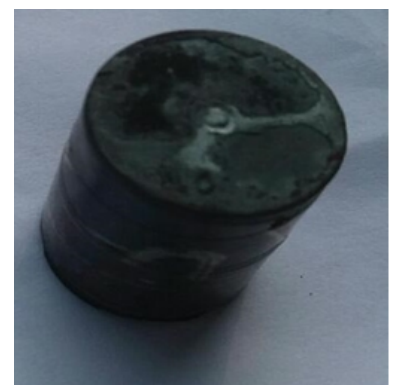

(a)

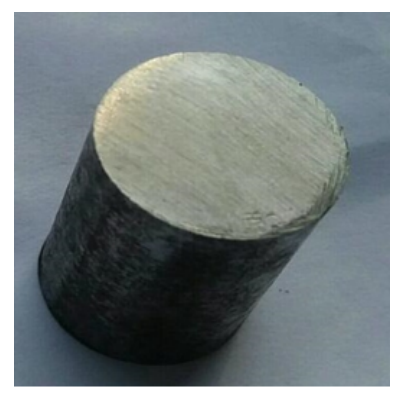

(b)

Fig. 1: Hardness of the specimen (a) before polishing and (b) after polishing

of mechanical properties of steel. It is necessary to use appropriate heat treatment temperature, soaking time and cooling conditions.

\section{Experimental Setup}

The material SAE 1040 was purchased from local market in Karachi, Pakistan. The chemical composition in weight percentage of medium carbon steel Grade SAE 1040 material was used for investigation, as shown in Table 1.

\subsection{Test Specimen Preparation}

Before to heat-treatment specimen were prepared according to ASTM standards. Tensile specimen were prepared according to ASTM E8/E8M standard [7]. Im-pact specimen were prepared according to ASTM E23-07a standard [9]. Hardness specimen were prepared according to ASTM E10-12 [8].

\subsection{Heat Treatment}

Specimen were austenitized at $700^{\circ} \mathrm{C}$, then cooled at different cooling mediums. Specimen were heated in a

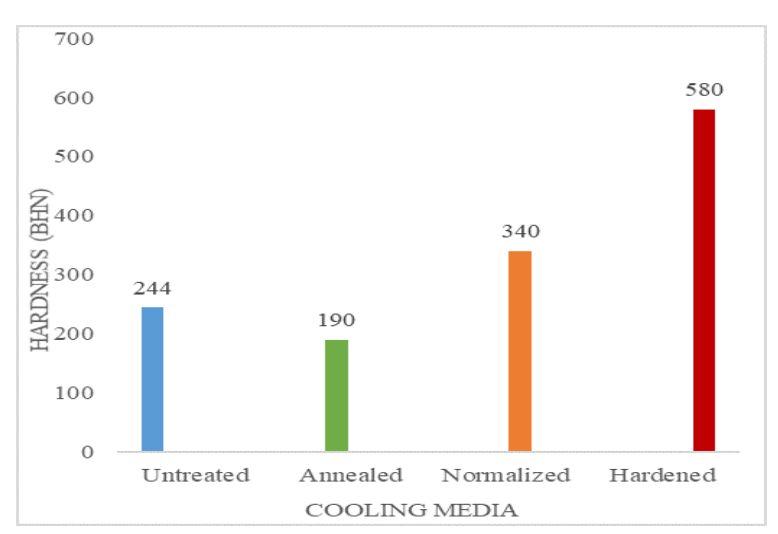

Fig. 2: Hardness of test specimen austenitized at $700^{\circ} \mathrm{C}$, soaked for 90 minutes then cooled in furnace, air and water

gas furnace. Furnace took 5 minutes to reach $700^{\circ} \mathrm{C}$ and the total time specimen remained in the furnace was 90 minutes. The specimens were then cooled in air and furnace and also quenched in water.

\subsection{Mechanical Properties}

Tensile test specimen were tested by computer based universal testing machine (UTM). Impact energy was tested with Izod impact tester. For hardness test, indention surface of specimen were polished using polishing machine, as shown in Figure 1. Hardness test was conducted with Brinell hardness testing machine with a scale $\mathrm{HB} / 30=$ Brinell hardness with a ball of $2.5 \mathrm{~mm}$ diameter, and with a test force of $187.5 \mathrm{~N}$ (19 kgf) applied for 15 second.

\section{Experimental Results}

This section presents the test results obtained by the experimental work.

\subsection{Hardness}

Hardness of untreated and heat-treated specimen results are illustrated in Figure 2 and Table 2. When material is heated at $700^{\circ} \mathrm{C}$, soaked for 90 minutes, then cooled in air and furnace, and quenched in water separately, it was observed that the furnace cooling lowers the hardness, while cooling in air and quenching in water increases the hardness as compared to the received specimen. Highest hardness was observed in water quenching. 


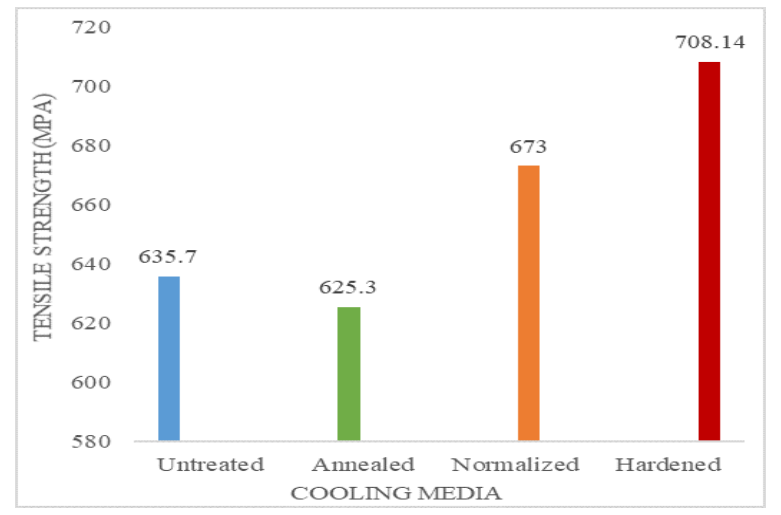

Fig. 3: Tensile strength of test specimen austenitized at $700^{\circ} \mathrm{C}$, soaked for 90 minutes then cooled in furnace, air and water

\subsection{Tensile Strength}

Throughout tensile strength measurement, additional tensile properties such as yield strength, breaking strength, Young's Modulus and elongation were analyzed. When material is heated at $700^{\circ} \mathrm{C}$, soaked for 90 minutes, cooled in air and furnace, and quenched in water separately, furnace cooling lowers the tensile strength, yield strength, breaking strength, Young's Modulus, but increases elongation. Whereas, cooling in air and quenching in water increases the hardness as compared to thereceived specimen. Highest tensile strength was observed in water quenching and highest elongation was observed in furnace cooling. Tensile strength of untreated and heat-treated specimen results are illustrated in Figure 3 and Table 2.

\subsection{Impact Energy}

When material is heated at $700^{\circ}$, soaked for 90 minutes, cooled in air and furnace, and quenched in water separately, it was observed that air and furnace cooling increase the impact energy as compared to the untreated specimen. Whereas, water quenching at austenitization temperature lowers impact energy. Highest impact energy was obtained by furnace cooling. Impact energy of untreated and heat-treated specimen results are illustrated in Figure 4 and Table 2 .

\section{Analysis \& Discussion}

Quenching is a rapid cooling rate compared to air and furnace cooling. It changes the crystalline structure of the steel. It can be left with a stronger, more brittle micro-structure, such as martensite or bainite,

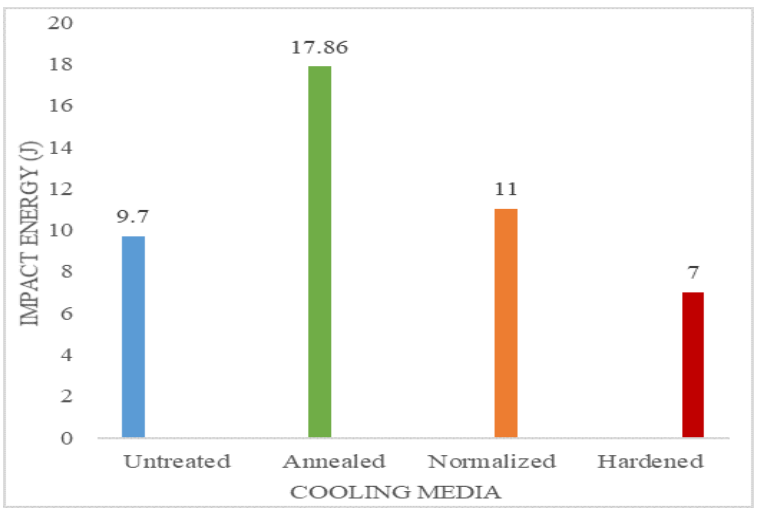

Fig. 4: Impact energy of test specimen austenitized at $700^{\circ} \mathrm{C}$, soaked for 90 minutes then cooled in furnace, air and water

depending on the carbon content and other alloying elements of the steel when it undergoes the quench hardening process. These micro-structures allow the steel to have increased strength and hardness. They do, however, leave the steel liable to cracking and with a great reduction in ductility. For this cause, following the quench hardening process, some steels are annealed or normalized [3]. Water quenching at austenitization temperature $700^{\circ} \mathrm{C}$, increases the hardness by $137.7 \%$, tensile strength by $11.4 \%$, yield strength by $79.28 \%$, breaking strength by $26.86 \%$, Young's Modulus by $2.78 \%$, but lowers the elongation by $10.49 \%$ and impact energy by $27.84 \%$ as compared to the untreated specimen.

Air cooling at austenitization temperature is usually known as normalizing process. Continuous cooling means, as the name suggests, that the steel temperature falls in a continuous manner rather than abruptly plummeting, as observed in water quenching. Steel will have ferrite in the pre-austenite grain boundaries surrounded by pearlite [3]. Air cooling at austenitization temperature $700^{\circ} \mathrm{C}$ improves the hardness by $39.34 \%$, tensile strength by $5.87 \%$, yield strength by $35.95 \%$, breaking strength by $0.57 \%$, Young's Modulus by $2 \%$, elongation by $17.75 \%$ and impact energy by $13.4 \%$ as compared to the untreated specimen.

Furnace cooling is often known as annealing process. Annealing produces the fully ferritic structure. Ferrite is a soft and ductile structure which in turn lessens the materials' hardness and ductility [3]. Furnace cooling at austenitization temperature of $700^{\circ} \mathrm{C}$ lowers the hardness by $22.13 \%$, tensile strength by $1.64 \%$, yield strength by $0.51 \%$, breaking strength by $4.08 \%$, Young's Modulus by $0.43 \%$, but increases the elongation by $67.94 \%$ and impact energy by $84.12 \%$. 


\section{Conclusion}

In this paper, a study to improve the mechanical properties of SAE 1040 by controlling the heat treatment conditions was presented. After heat treatment, the specimens were tested according to ASTM standards. The following conclusions are drawn on the basis of the current analysis:

1) In order to improve the mechanical properties of steel, it is important to properly choose the austenitizing temperature, the holding time and the cooling condition.

2) Heat treatment at austenitizing temperature of $700^{\circ} \mathrm{C}$ for 90 minutes followed by quenching in water resulted highest value of hardness, tensile strength, yield strength, breaking strength, and Young's Modulus as compared to the untreated and furnace and air cooled.

3) Highest values of impact energy and elongation were observed in furnace cooling at austenitization temperature of $700^{\circ} \mathrm{C}$ soaked for 90 minutes.

4) Air cooling at austenitizing temperature of $700^{\circ} \mathrm{C}$ for 90 minutes improves the mechanical properties as compared to the untreated specimen.

5) Difference of cooling rate in furnace, air and water media highly influenced the mechanical properties, i.e. fast cooling rate enhanced the mechanical properties hardness, tensile strength, yield strength, breaking strength, and Young's Modulus. Whereas, the slow cooling rate enhanced the impact energy and elongation.

This study concluded from the overall results that the mechanical properties of grade 1040 cast steel are improved by the use of heat treatment processes.

\section{References}

[1] Harari, Yuval Noah. "Sapiens. A Brief History of Humankind/Yuval Noah Harari." (2014).

[2] Madan, Jatinder, et al. "Energy performance evaluation and improvement of unit-manufacturing processes: injection molding case study." Journal of Cleaner Production, vol. 105, pp. 157-170, 2015.

[3] Verhoeven, John D. Steel metallurgy for the nonmetallurgist. ASM International, 2007.

[4] Prasad, C. T., Giribabu, S., Umesh, "Effect of cooling rate on hardness of AISI 1040 Steel" International journal of engineering sciences research technology, 2018.

[5] Johnson, Oluwagbenga T., et al. "Mechanical Properties of Heat-treated Medium Carbon Steel in Renewable and Biode-gradable Oil." Procedia Manufacturing, Vol. 35, pp. 229-235, 2019.

[6] Murugan, V. K., and P. Koshy Mathews. "Effect of tempering behavior on heat treated medium carbon (C $35 \mathrm{Mn}$ $75)$ steel." International Journal of Innovative Research in Science, engi-neering and technology, Vol. 2, No. 4, pp. 9459540, 2013.
[7] ASTM, I. "ASTM E8/E8M-16a: Standard Test Methods for Tension Testing of Metallic Materials." West Conshohocken, PA, USA: ASTM International, 2016.

[8] ASTM International. Standard test method for Brinell hard-ness of metallic materials. ASTM International, 2012.

[9] Standard, AST M, "Standard Test Methods for Notched Bar Impact Testing of Metallic Materials", E23-07a, ASTM Inter-national, West Conshohocken, PA, 2007.

[10] Qasim, Bilal Mohammed, et al. "Influence Of Heat Treatment On The Absorbed Energy Of Carbon Steel Alloys Using Oil Quenching And Water Quenching." Journal of Mechanical Engineering Research and Developments, Vol. 41, No. 3, pp. 43-46, 2018. 